\title{
Attitudes of Young Dhatki Speakers towards Their L1 and Its Maintenance
}

\author{
Hina Jhanjhi* Ambreen Shahryar \\ English Language Development Center, Mehran University of Engineering and Technology
}

\begin{abstract}
This qualitative study explores the attitudes that speakers of Dhatki as a first language (L1) hold towards their mother tongue and their willingness to maintain the language in the future. The study also touches areas such as young speakers of Dhatki as L1 and their interest in learning different languages. The research data was collected through the semi-structured interviews based on multiple sessions. Grounded theory has been used as the approach to execute the study. The data was analyzed and turned into codes and themes. The participants do not think Dhatki has any instrumental value because it is not used in schools and other official domains around the country. Although Dhatki's instrumental value is low, the children hold positive attitudes towards maintenance of their L1. The children do not think that Dhatki should be used in the school as the medium of instruction because it is not used in the rest of the country and it could cause a hindrance in their learning and job seeking. The children have integrative motivation to continue learning and maintaining Dhatki because it is a part of who they are. They want to be able to stay in contact with their family and close ones to share their world experiences. However there are a few children who are not interested in maintaining Dhatki as their L1 and transfer it to the next generation because Dhatki has a low instrumental value. The situation of Dhatki can be improved by introducing it as a subject in the school and organizing programs to celebrate the Dhatki language and culture. To stop language loss due to language shift and language death, it is important to improve a language's instrumental value.
\end{abstract}

Keywords: Dhatki, minority language, Thar, attitudes, young speakers, minority L1, minority maintenance,

DOI: $10.7176 /$ JLLL/85-02

Publication date: January $31^{\text {st }} 2022$

\section{Introduction}

This is a sociolinguistic study that intends to explore the attitudes of L1 Dhatki speakers towards their L1 and its maintenance along with their possible reasons. Attitudinal studies are usually carried out using quantitative studies but this study employs qualitative method to explore and understand the attitudes of the Dhatki L1 speakers in depth. Dhatki like majority of languages in Pakistan is treated as a minority language or a colloquial language despite its native population. Colloquial language Johan Van Hoorde (1998, quoted in Crystal 2014) describes as a language which is a language that people use to express their feelings and emotions in but it is a language that does not have any official domains to be practiced in.

\subsection{Context of the Study}

There are around 7117 languages spoken in the world (Ethnologue, 2020). All of these languages have their own peculiarities, ecology and community. These languages are not just a means of communication, these languages are carriers of cultural knowledge which was built over centuries. Death of even one language out of $7100+$ languages means losing a part of the shared human heritage, losing the cultural and local knowledge endemic to the environment of the language. Pakistan is home of 74 languages yet only a few languages are given an official domain including Urdu, Sindhi and Balochi. The rest of the languages are not given any importance whatsoever. Most of the languages spoken in Pakistan are considered minority languages in Pakistan, Dhatki being one of them. Low instrumental value for any language could pose a death threat to it.

\subsection{Problem Statement}

Slavik (2001) states that it is important that a language has a high instrumental value in order to survive. Kuncha and Bathula (2004) found that negative attitudes towards L1 affects maintenance of L1 negatively. However, a few studies like Jee (2018) and Shin (2016) suggest that while dealing with minority languages, integrative motivation plays a more important role in maintaining the minority L1 than the instrumental motivation.

\subsection{Aim and Objectives of the Study}

The aim of this study is to explore the attitudes that speakers of Dhatki as their L1 hold towards Dhatki and its maintenance. The study intends to fulfil the aim by achieving these objectives:

i. $\quad$ To explore the attitudes that L1 Dhatki speakers hold towards their mother tongue.

ii. To explore the factors that affect the attitudes of Dhatki speakers towards their L1 
1.4. Purpose of the Study

This study aims to explore the attitudes of the young Dhatki speakers towards their L1 and why they have those attitudes. It can help in language policy and language planning to stop language death or language shift which the minority languages are prone to.

\subsection{Limitations of the Study}

The participants of this study are aged between 11-16 years. All of the young participants are female. The interview sessions could not be extended to more than 2 sessions due to COVID-19 SOPs restrictions and time restraints.

\section{Literature review}

Holmes (2001) argues that certain political, economic and social changes can cause language shift in a language community. Holmes (1990) argues that people's attitudes towards their L1 also have a great influence on the various levels of language shift. Kuncha and Bathula (2004) found in their study that when a language community does not have positive attitudes towards their mother tongue in comparison to dominant languages, it affects the L1 maintenance negatively. It is found by Holmes (ibid.) that if the L1 speakers of a minority language have positive attitudes towards their L1 then they would use their L1 in various domains more often hence deterring language shift to a dominant language.

The examples of researches like the one by Siebenhütter's (2021) on Kui also shows the same that a language can survive if its speakers have positive attitudes towards speaking it. Even though the language has a low instrumental value, the speakers have positive attitudes towards maintaining it therefore Kui continue to survive side by side with Thai language.

However, it is not always the case and people may develop negative attitudes towards their language due to its low instrumental value. Abbasi \& Aftab (2020) conducted a study on Dhatki speakers in the urban settings to find out about the languages used by the Dhatki speaking youth and their language preferences according to the situation. Urdu speaking youth to find out their language attitudes. They concluded in their study that the youth hold negative attitudes towards their mother language Dhatki.

\section{Research Methodology}

3.1 Introduction

Usually, the quantitative method is used to measure the attitudes of people towards languages but I have used the qualitative method to explore the attitudes of the participants and the reasons behind those attitudes.

\subsection{Research Approach and Design}

Grounded Theory is used as the research approach for this study's data analysis. The data was analyzed to identify different codes which were later used to generate different themes. The research design for this study is interpretivist.

\subsection{Research Tool}

Semi-structured interviews were used to collect the data from the participants. The semi-structured interviews allow the data to richer. The guiding questions for the semi-structured interviews were only used to nudge the participants in one direction or the other.

\subsection{Data Collection and Analysis Process}

A total of 23 participants were selected for the study sample including 20 children and 3 teachers belonging to a government elementary school in Chachro. Purposive sampling was used as the sampling method to gather the richest data possible. The data collection was carried in the school to which the participants belong. The interviews were recorded on the researcher's mobile phone after written and oral consent from the participants' side. The data was analyzed thematically to identify the different themes after open and axial coding.

\section{Data Analysis}

\subsection{Recurring Themes}

These are main themes that were identified:

i. Limited domains of Dhatki

ii. Underdeveloped entertainment industry

iii. Low instrumental value

iv. Better opportunities provided by other languages

v. Preference towards usage of dominant languages in education

vi. Dhatki as a marker of identity 


\section{i. Limited Domains of Dhatki}

More than half of the participants are of the opinion that Dhatki language has only a few limited domains which are not official or formal. Dhatki is not present in any formal domain like education, administration or jobs market. ii. Underdeveloped Entertainment Industry

The realm of entertainment keeps a language alive but the participants of this study admit to opting for entertainment in other languages than their L1. There are no Dhatki channels on the national television, there are no Dhatki newspapers or children's magazines. The Dhatki music industry is not that well developed either. The music, lyrics and videography are sub-quality when compared to Urdu and Sindhi entertainment industry.

iii. Low Instrumental Value of Dhatki

Dhatki is a minority language with a very few domains as previously mentioned. Like many native speakers of minority languages, speakers of Dhatki also consider it to be a language with low instrumental value. The language is not taught in the schools and is not used in the offices anywhere. According to all children Dhatki does not prove instrumentally useful to the children.

iv. Better Opportunities Provided by Other Languages

All children have shown their keen interest in learning major languages. There are two main reasons for their interest in learning majority languages. The opportunities provided by those majority languages being one reason. Another reason is their intrinsic interest in languages and other cultures. Some of these languages include not only Urdu and English but also Chinese and Arabic. The latter two are the center of children's intrinsic motivation.

v. Preference towards Dominant Languages for Education

When asked if children would like to get education in Dhatki, majority of the children did not agree to the idea. The majority of children are of the opinion that they would be left behind in education if they are schooled in Dhatki. Some children are of the opinion that Sindhi instead of English or Dhatki should be used to teach the subjects. While a few children agree to the idea of Dhatki being used as a medium of instruction saying, "It will be easier to understand the courses (in Dhatki)."

vi. Dhatki as a Marker of Identity

Despite everything, 17 out of 20 children express that they wish to maintain their L1 and pass it on to the future generations. However 3 out of the 20 participants are of the opinion that Dhatki does not serve any major function in their life therefore they would not transfer their L1 to the next generations.

\subsection{Reasons for Children's Attitudes}

Some of the reasons for children's positive attitudes towards their L1 include not wanting to lose contact with relatives and family. Dhatki is the language that is used in the homes almost exclusively and among Dhatki friends too. Individuals do not want to let go of their L1 because they feel like they would lose a part of their own identity. Children are integratively motivated to maintain Dhatki. As for the negative attitudes towards L1 only two main reasons could be identified, one of them being Dhatki's low instrumental value. Another reason for negative attitudes is the low exposure of Dhatki in the mainstream media and official usages.

\section{Theory Building}

If a language has a strong integrative value, it will continue to survive. However there will always be threats to its survival. These threats include language shift and language death. No population unanimously decides to abandon its native language one day, the process is gradual and may take anywhere from a decade to a century. To improve Dhatki's position its aesthetic value should be endorsed by introducing new forms of entertainment in Dhatki language like television programs, kids' magazine, recipe books fairs and festivals to celebrate Dhatki culture, folklore, jokes, traditions and legends, Dhatki Heritage day held at schools. Dhatki farmers' magazines and newspapers. Apart from that improving instrumental value of Dhatki can improve chances of the language's survival to a great extent. For improving Dhatki's instrumental value the primary schooling should be done to strengthen the speakers' belief that their minority L1 is worth maintaining. Rewards point system should be introduced in school to reward children that know their L1 well to improve Dhatki's situation.

To conclude, this study has found that more young participants are interested in transferring Dhatki to their younger generation than not. The major identifiable reason for this being the fact that Dhatki speakers like to maintain close relationships with their family and community. The threat of language death and language shift is low for Dhatki currently however the threat is not absent.

\section{References}

Abbasi, M. H \& Aftab, M. 2020 Mother Tongue or the Other Tongue? The Case of Dhatki-Speaking Urban Youth. Balochistan Journal of Linguistics. 7. 81-92. 
Jee, M. J. (2018). Heritage language proficiency in relation to attitudes, motivation, and age at immigration: a case of Korean-Australians. Language, Culture and Curriculum, 31(1), 70-93. https://doi.org/10.1080/07908318.2017.1342653

Kuncha, R. M. and Bathula, H. (2004). "The Role of Attitudes in Language Shift and Language Maintenance in a new Immigrant Community”. Working Paper No. 1. Auckland, New Zealand.

Shin, S., Ko, S., \& Rue, Y. (2016). Heritage language learning: A needs analysis study of Korean-Australian tertiary students. Journal of Korean Language Education, 27(1), 111-155.

Siebenhütter, S. (January 01, 2021). Language practices and attitudes among young minority language speakers in Thailand. Journal of Multilingual and Multicultural Development, 42, 7, 595-620. (pp. 1-10). London: Routledge Curzon.

Slavik, H. (2001) Language Maintenance and Language Shift Among Maltese Migrants in Ontario and British Columbia. Walter de Gruyter Publishers. 